\title{
INFORMACIONI SISTEM ZA PRAĆENJE TOKA ALATA U MALOM PROIZVODNOM PREDUZEĆU
}

\section{INFORMATION SYSTEM FOR MONITORING TOOL FLOW IN THE SMALL PRODUCTION ENTERPRISE}

\author{
Dejan Božić, Fakultet tehničkih nauka, Novi Sad
}

\begin{abstract}
Oblast - MAŠINSTVO
Kratak sadržaj - Informacioni sistemi u proizvodnim pogonima malih i srednjih preduzeća značajno mogu da utiču na povećanje produktivnost $i$ ekonomičnosti. Osnovni predmet i cilj istraživanja u ovom radu se odnosi na istraživanje vremenskih gubitaka usled nepostojanja informacionog sistema vezanog za praćenje toka alata, kao i prikaz idejnog rešenja ovog sistema.

Ključne reči: Informacioni sistem, Vremenski gubici, Tok alata, Malo proizvodno preduzeće

Abstract - Information systems in the production facilities of small and medium enterprises can significantly increase productivity and economy. The main subject and goal of the research in this paper is to investigate time losses in the midst of the lack of information system related to monitoring the flow of tools, as well as the presentation of the conceptual solution of this system.
\end{abstract}

Keywords: Information system, Time loses, Tool flow, Small production enterprises

\section{UVOD}

"JOMI-ING" je malo preduzeće koje prati savremeni tehnološki napredak, kroz nabavku modernih mašina renomiranih svetskih proizvođača, kao i visokokvalitetnih alata, pribora i mernih sistema, čime se izvršavaju brojni izuzetno složeni i precizni zadaci u skladu sa zahtevima kupaca. Proizvodni program čini širok spektar izrade delova i montaže sklopova za razne industrijske potrebe: autoindustriju, farmaceutsku i optičku industriju [1].

Kao predmet istraživanja nameće se sistematizacija i unapređenje proizvodnje posmatranog preduzeća, gde se na prvo mesto postavlja razvoj i implementacija informacionog sistema koji je prilagođen potrebama ovog malog preduzeća. Osnovni cilj ovog rada odnosi se na postavku idejnog rešenja informacionog sistema za praćenje toka alata kao jedne od vitalnih aktivnosti za unapređenje poslovanja posmatranog preduzeća.

\section{INFORMACIONI SISTEMI U PREDUZEĆU}

\subsection{Osnove informacionog sistema}

Kvalitetno rukovođenje preduzećem nije moguće zamisliti bez neophodnog resursa koji predstavlja informacija. Dobra i pravovremena odluka iziskuje da informacija mora biti tačna, precizna i u pravo vreme.

\section{NAPOMENA:}

Ovaj rad proistekao je iz master rada čiji mentor je bio dr Dejan Lukić, vanr. prof.
Informacioni sistem predstavlja sistem koji će na osnovu formalizovanih procedura obezbediti upravljanje na bazi informacija iz internih i eksternih izvora, a te odluke će se koristiti za potrebe planiranja, rukovođenja i kontrole aktivnosti. Informacioni sistem u širem smislu predstavlja kompletan sistem protoka, razmene i obrade informacija. Takođe, ovaj pojam se smatra širim od pojma informacione tehnologije, a zanimljivo je da čak i ne mora biti baziran na računarskoj tehnologiji. Informacioni sistem predstavlja skup organizovanih komponenti koje omogućuju [2]: Registrovanje; Prikupljanje; Prenos; Obradu; Skladištenje; Analizu i Distribuciju informacija za različite namene.

Informacioni sistem, takođe, može da se predstavi kao organizovani skup međusobno povezanih komponenti, kao što su: Softverski resursi; Hardverski resursi; Mrežni resursi; Resursi podataka i Ljudski resursi.

Pod softverskim resursima podrazumevaju se programi i procedure, hardverski resursi obuhvataju računarske uređaje i medije, mrežni resursi komunikacione medije i računarske mreže, resursi podataka obuhvataju baze podataka i znanja, a ljudski resursi uključuju specijaliste i korisnike informacionih tehnologija.

\subsection{Motivi implementacije informacionih sistema}

Preduzeća se moraju konstantno razvijati kroz unapređenje znanja, praćenje trendova i noviteta. Ključ uspeha predstavlja želja za uspehom, razumevanje noviteta $\mathrm{i}$ implementacija isključivo optimalnog odnosa noviteta u postojeće preduzeće koje će jasno unaprediti poslovanje i olakšati zaposlenima određene aktivnosti. Neki od motiva koji odlučuju da se izvrši implementacija informacionog sistema mogu biti sledeći:

- Integrisanje informacija iz odnosa sa kupcima, posebno u vezi sa porudžbinama kupaca

- Standardizovanje i ubrzavanje proizvodnih procesa

- Integrisanje finansijskih informacija

- Redukovanje zaliha

\subsection{Načini implementacije informacionih sistema}

Implementacija ovakvih rešenja može da traje od jedne do pet godina, iako je taj termin značajno kraći ukoliko dobavljači predstavljaju vremenski zahtev implementacije. Postoje sledeći načini implementacije:

BigBang strategija - Ova strategija podrazumeva da se u istom momentu pređe sa jednog na drugi način poslovanja u skladu sa ERP zahtevima. Zahteva se da kompletan ERP sistem bude do detalja urađen i da se po prelasku na taj sistem koristi u punom kapacitetu. Upravo zbog toga 
se dešavaju propusti koji se moraju ispraviti u što kraćem roku. Uspeh implementacije ERP sistema na ovaj način je vidljiv tek nakon nekoliko godina.

Franchising strategija - Karakteristična je za velike korporacije gde postoji mreža sa udaljenim poslovnim jedinicama koje poseduju visok stepen autonomije upravljanja. Franchising strategija podrazumeva instalaciju, podešavanje i puštanje u rad jedne licence ERP sistema $\mathrm{u}$ određenoj poslovnoj jedinici. Ako implementacija prođe uspešno, ona postaje referentna za nove implementacije u ostalim poslovnim jedinicama.

Slam Dunk strategija - Ova strategija ima za cilj implementaciju informacionog sistema samo u okviru ključnih procesa poslovnog sistema. $\mathrm{Na}$ osnovu toga pri implementaciji ERP sistema, takav sistem se bira i prilagođava već postojećim poslovnim procesima. Pogodnosti strategije su što je niskog rizika upravo zbog toga što se realizuje postepeno, pa se stoga ne vrši značajan reinženjering, već se samo uvodi novi alat za podršku poslovnim procesima.

\section{TOK INFORMACIJA I ALATA U PREDUZEĆU}

\subsection{Strategije proizvodnje u preduzeću}

Osnovne strategije proizvodnje prema uticaju kupca na proizvod, možemo podeliti na sledeći način [3, 4]:

Proizvodnja za zalihe - MTS (Make to stock) Predstavlja strategiju kod koje se gotovi proizvodi skladište i čekaju kupca. Karakteristike strategije su kratko vreme od narudžbine do isporuke, ali su vreme i troškovi skladištenja veliki, dok je uticaj kupca na karakteristike proizvoda mali.

Montaža prema narudžbi - ATO (Assembly to order) Predstavlja strategiju kod koje proizvođač vrši montažu gotovih proizvoda koje čine modularni delovi i podsklopovi prema zahtevu kupca.

Proizvodnja prema narudžbi - MTO (Make to order) Predstavlja strategiju kod koje proizvođači čekaju narudžbu od kupca da bi prilagodili proizvod koji se sastoji od gotovih modularnih komponenti i komponenti koje je tek potrebno projektovati i izraditi.

Inženjering prema narudžbi - ETO (Engineering to order) - Predstavlja strategiju kod koje kupac definiše specifikaciju i funkcionalnost proizvoda, a proizvođač projektuje i proizvodi odgovarajući proizvod prema dostavljenoj specifikaciji.

Preduzeće je najviše orijentisano na proizvodnju/pružanje usluga izrade delova i sklopova prema narudžbi i tehničkoj dokumentaciji kupca. Shodno tome u nastavku će se razmatrati organizacija rada službi preduzeća i tokovi informacija prema ovoj strategiji poslovanja.

\subsection{Organizaciona struktura preduzeća}

Cilj kojem teže preduzeća koja su pretežno orijentisana ka pojedinačnoj i maloserijskoj proizvodnji, predstavlja ispunjenje zahteva kupca. Zbog jasnijeg prikaza funkcionisanja posmatranog preduzeća na slici 1 . dat je tok praćenja narudžbi u preduzeću, od momenta dobijanja zahteva od kupca pa sve do isporuke proizvoda [5].

U okviru tabele 1 detaljno su objašnjeni koraci toka informacija sa slike 1 , gde su predstavljene i informacije o toku alata u preduzeću. Informacije o toku alata vezane su za više odeljenja preduzeća, tako da je to ujedno i uvod za dalju analizu toka podataka o alatima.

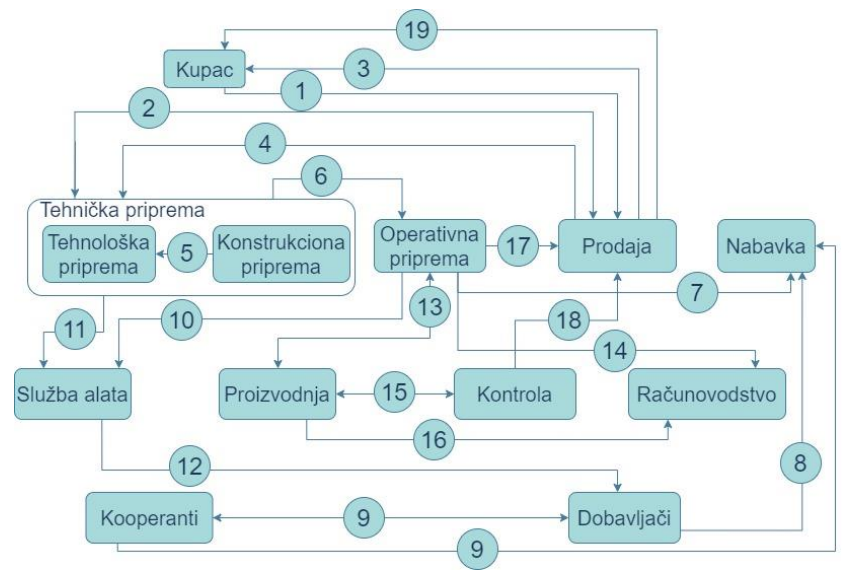

Slika 1. Tok aktivnosti u preduzeću JOMI-ING

Tabela 1. Aktivnosti pri praćenju narudžbina

\begin{tabular}{|c|}
\hline TOK \\
\hline 1 \\
\hline
\end{tabular}

Kupac kontaktira preduzeće (prodaju) kako bi poručio proizvod prema svojim zahtevima.

Predaja dostavlja zahtev/narudžbu kupca službi tehničke pripreme proizvodnje. Konstrukciona priprema proizvodnje razmatra novitet proizvoda i da li je potrebna njena aktivnost. Ukoliko narudžbina sadrži crteže proizvoda prosleđuje se u 2 tehnološku pripremu proizvodnje. Nakon toga, vrše se konsultacije između tehnološke pripreme proizvodnje, operativne pripreme proizvodnje i nabavke u cilju definisanja mogućnosti izrade, kapaciteta, grubih rokova isporuke i procene troškova - cene isporuke.

Prodaja šalje kupcu ponudu (koncept proizvoda - ukoliko postoji takav zahtev, rokove isporuke i cenu) na odobravanje. Ukoliko se kupac slaže sa ponudom, potpisuje se ugovor o izradi i isporuci proizvoda.

Kada se ugovor potpiše, prodaja izdaje tehnićkoj pripremi nalog. Tehnička priprema, operativna priprema proizvodnje i nabavka usaglašavaju rokove (nabavke, završetka konstrukcione i tehnološke dokumentacije, početka i završetka proizvodnje termin isporuke proizvoda).

$\mathrm{U}$ okviru tehničke pripreme proizvodnje, konstrukciona priprema proizvodnje šalje tehnološkoj pripremi proizvodnje 5 konstrukcionu dokumentaciju. Vrši se izrada i dopuna tehnološke dokumentacije (sadržaj tehnološkog procesa, karte operacija, upravljački programi...). Definisanje troškova proizvodnje.

6 Predaja konstrukcione i tehnološke dokumentacije u službu operativne pripreme proizvodnje.

Provera stanja zaliha pripremaka, komponenti (delova i sklopova) i dr. Slanje zahteva za nabavku pripremaka i komponenti službi nabavke.

8 Kontakt sa dobavljačima i odgovor o rokovima i količinama isporuke pripremaka, komponenti (delova i sklopova) i dr.

Kontakt sa kooperantima i odgovor o rokovima i količinama dostave robe.

10 Provera ispravnosti postojećih alata, pribora, merila, uređaja i dr. i narudžba za popravku istih, izradu ili porućivanje novih.

11 Tehnička dokumentacija (konstrukciona i tehnološka dokumentacija) specijalnih alata, pribora, merila, uređaja i dr.

12 Porudžba alata, pribora, merila i uređaja od dobavljača Lansiranje konstrukcione dokumentacije, tehnološke dokumentacije i radnih naloga u proizvodnju. Povratne informacije o realizaciji radnih naloga iz proizvodnje u operativnu pripremu proizvodnje.

\begin{tabular}{|c|l|}
\hline 14 & $\begin{array}{l}\text { Lansiranje dokumentacije iz operativne pripreme proizvodnje u } \\
\text { računovodstvo. }\end{array}$ \\
\hline 15 & $\begin{array}{l}\text { Komunikacija između proizvodnje i kontrole o ispravnosti } \\
\text { izrađenih proizvoda. }\end{array}$ \\
\hline 16 & Lansiranje proizvodne dokumentacije u računovodstvo. \\
\hline 17 & $\begin{array}{l}\text { Kontinualne informacije o prodaji iz proizvodnje o stanju } \\
\text { dovršenosti proizvoda, poteškoćama, eventualnim kontaktima sa } \\
\text { kupcima i dr. }\end{array}$ \\
\hline 18 & Obaveštenje službe prodaje o završetku proizvodnje. \\
\hline 19 & Isporuka gotovih proizvoda kupcu. \\
\hline
\end{tabular}




\subsection{Vremenski gubici programera}

Razvoj informacionog sistema za praćenje alata uslovljen je vremenskim gubicima programera, te je zbog toga dat uvid u kriterijume njihovog nastanka. Posmatrani su razni kriterijumi u toku od tri radne nedelje (15 radnih dana), koji su dati u nastavku.

Kao prvi parametar za uvid u vremenske gubitke programera izdvaja se broj kreiranih NC programa na dnevnom nivou, slika 2 .

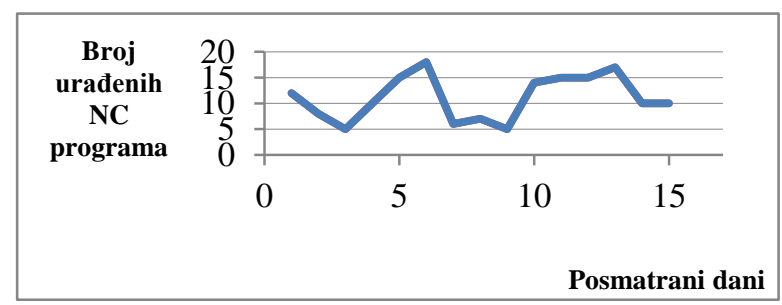

Slika 2. Broj urađenih NC programa na dnevnom nivou za vremenski period od tri nedelje

Kao sledeći parametar uzet $\mathrm{u}$ razmatranje jeste broj alata koji se koriste na dnevnom nivou. Na slici 3 dat je uvid u dnevni prosek korišćenja alata (brojčane vrednosti).

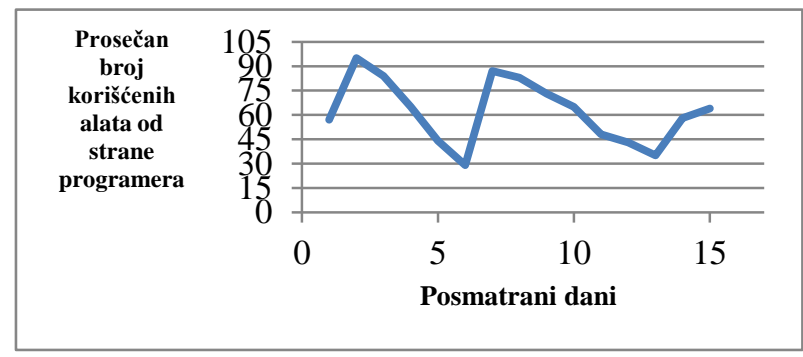

Slika 3. Prosečan broj dnevno korišćenih alata za vremenski period od tri nedelje

Slika 4 pokazuje koliko je programer puta imao konsultacije vezano za određeni alat, ili je sam tražio alat u alatnici, na dnevnom nivou.

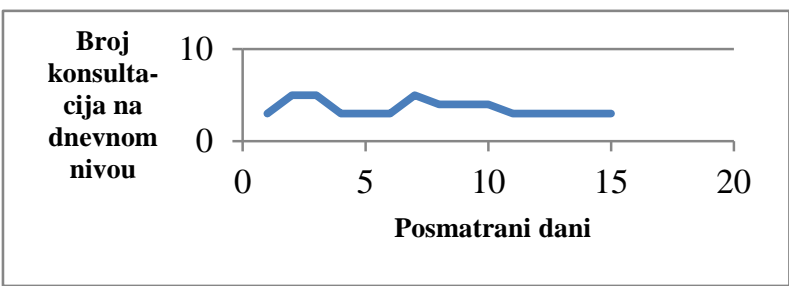

Slika 4. Broj konsultacija vezane za alate na dnevnom nivou za vremenski period od tri nedelje

$\mathrm{Na}$ slici 5. prikazani su vremenski gubici programera. Vremenski gubici variraju, a prosek posmatrane tri nedelje je oko 15 minuta dnevno. U posmatranom periodu od tri nedelje izgubljeno je ukupno 225 minuta sa stanovišta programera, što jeste ozbiljan gubitak, pogotovo ako se uzme $\mathrm{u}$ obzir da $\mathrm{u}$ pogonu ima više programera mašina.

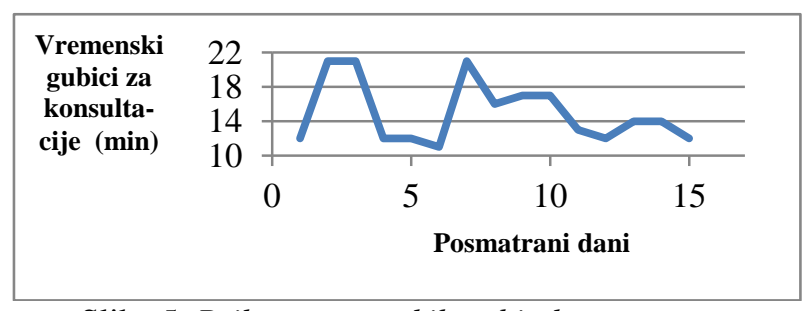

Slika 5. Prikaz vremenskih gubitaka programera

\section{IDEJNO REŠENJE INFORMACIONOG SISTEMA ZA PRAĆENJE TOKA ALATA}

Pošto se informacije vezane za tok alata, u posmatranom preduzeću tiču menadžera kvaliteta i nabavke, programera i šefa proizvodnje (gde se podrazumevaju i operateri), prikazani koncept rešenja biće predstavljen iz njihovog ugla. Na samom startu definisane su informacije baza podataka za alate, mašine i operatere. Aplikacija koja je korišćenja za formiranje elemenata baze podataka je MS Excel, a aplikacija u okviru koje su kreirani različiti interfejsi kao i povezivanje baza podataka je MS Access. $\mathrm{Na}$ slici 6. prikazane su inormacije baze podataka alata, $\mathrm{u}$ okviru koje su trenutno uneti opšti podaci.

Ovu bazu podataka informacijama pohranjuje menadžer za kvalitet i nabavku. Ako se kupi novi alat, on ima dužnost da informaciju unese $u$ bazu, tako što upisuje sve potrebne podatke ili u koloni "Količina" ažurira novo brojno stanje u skladu sa brojem novih alata i trenutno postojećih u okviru preduzeća. Pod kolonom "Tip alata" podrazumeva se vrsta alata, pa je zbog lakše pretrage prvo je stavljena vrsta alata, pa tek onda podvrsta (kao na primer glodalo_vretenasto ili glodalo_ceono).

U koloni "Prečnik" upisuje se prečnik alata, dok se u kolonu "Dubina" unosi maksimalna dubina koju alat može da obrađuje. Kolone "M_A" i "M_O" predstavljaju materijal alata i materijal obratka, koji su značajni ako se koristi iMachining u okviru SolidCam - a gde se unošenjem ovih podataka, softverskim putem određuju optimalni režimi obrade prema kriterijumu maksimalnog kvaliteta obrađene površine ili maksimalne količine skinute strugotine. Kolone "Brz. Rezanja", "Pomak" i "Dubina" predstavljaju preporučene režime obrade prema katalozima proizvođača alata.

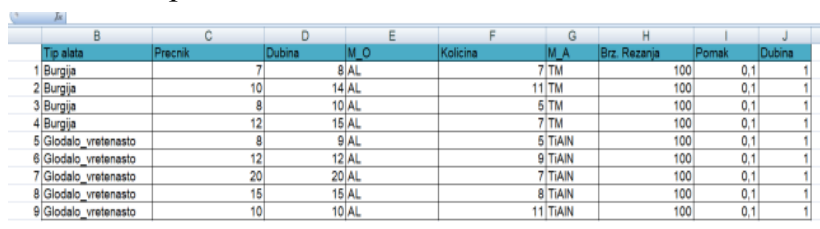

Slika 6. Prikaz elemenata baze podataka alata

Baza podataka operatera sadrži ID operatera i bitna je sa aspekta praćenja mesta lokacije preuzetog alata.

Baza podataka mašina, sadrži 8 obradnih centara za glodanje (Obradni centar G) i 3 obradna centra za struganje (Obradni centar $S$ ). Pored naziva mašine u bazi se nalaze geometrijske karakteristike mašina ("X osa","Y osa" i "Z osa") i maksimalni broj obrtaja glavnog vretena mašine.

Razliku interfejsa prave različite potrebe zaposlenih u tom smislu, da ako na primer programer želi da izabere mašinu na kojoj će se vršiti obrada, on treba da zna i karakteristike mašine kako ne bi kreirao i poslao NC program na obradni centar koji zbog dimenzija radnog prostora nije odgovarajući. Sa druge strane, ako operater uzima alat iz alatnice po nalogu programera - tehnologa, njemu je važno da ubeleži na kom obradnom centru će se nalaziti alat.

\section{Interfejs operatera}

$\mathrm{Na}$ slici 7. prikazan je interfejs operatera za preuzimanje alata iz magacina. Dužnosti operatera su da izabere iz padajućeg menija polja koja se odnose na alat koji bira, zatim na koju mašinu nosi alat i na kraju koji operater je 
zadužio alat. Ukoliko postoji potreba za nekom napomenom unosi ga u polje sa desne strane. Ovaj interfejs automatski beleži vreme kada je operater preuzeo alat.

Isti interfejs se koristi i kod vraćanja alata, s tim što postoji dodatan deo "Lom alata", gde je potrebno uneti reč "DA" ukoliko je došlo do loma alata (da bi se pravovremeno poručila zamena) ili uneti reč "NE" ukoliko nije došlo do oštećenja. U okviru "NAPOMENA" poželjno je rečima opisati ukoliko je došlo do sitnijih oštećenja alata ili slično.

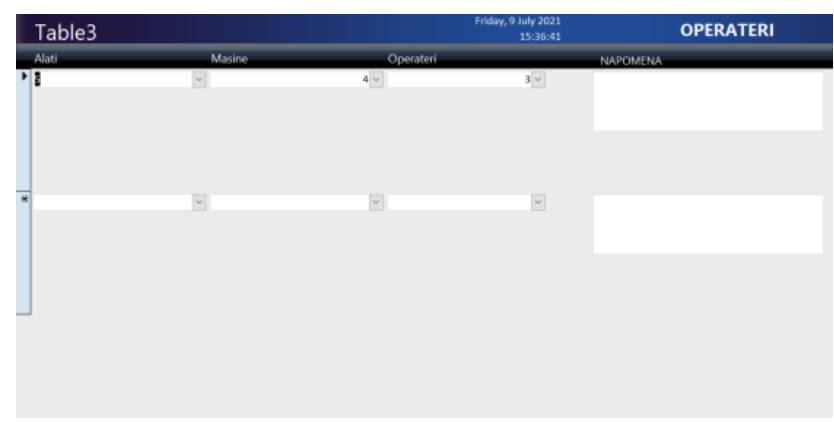

Slika 7. Izgled interfejsa za preuzimanju alata

Interfejs menadžera kvaliteta i nabavke

Interfejs za uvid u raspoloživost alata po pitanju stavki "Alati" i "Mašine" su identični sa prethodno opisanim slikama. Dodatna polja predstavljaju "Količina" i "Raspoloživo", slika 8. Na osnovu izbora alata, automatski se popunjavaju sledeća polja, pa se tako dobija "Količina" pod kojom se podrazumevaju svi alati koji se nalaze $\mathrm{u}$ preduzeću (koji se trenutno koriste i koji se ne koriste). Ovaj broj je važan kako bi menadžer kvaliteta i nabavke, u slučaju manjeg broja alata, pravovremeno naručio dodatne količine. Pod stavkom "Raspoloživo" podrazumeva se broj alata koji se trenutno ne koriste na mašinama, a raspoloživi su za korišćenje.

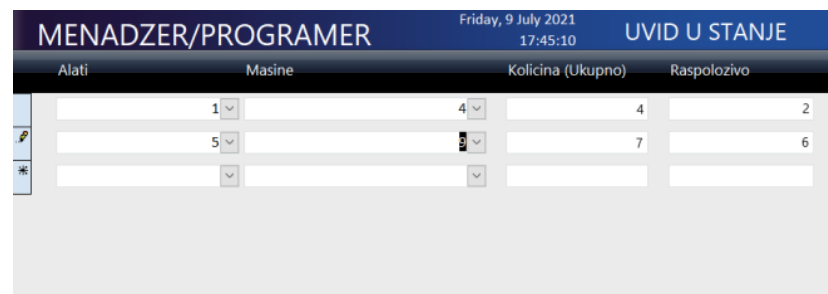

Slika 8. Interfejs za uvid u raspoloživost alata

\section{Interfejs programera}

$\mathrm{Na}$ slici 9. prikazan je izgled interfejsa planiranih alata koji koristi programer. U okviru njega može se birati tačno određeni alat i mašina na kojoj se planira koristiti alat, kao i dodatna napomena ukoliko postoji potreba. Padajući meniji pod stavkama "Planirani alati" i "Mašine" su identični sa opisom prethodnih. Ovaj deo je važan sa aspekta da označavanjem planiranih alata za upotrebu, drugi programer vidi podatak i u skladu sa tim planira alate.

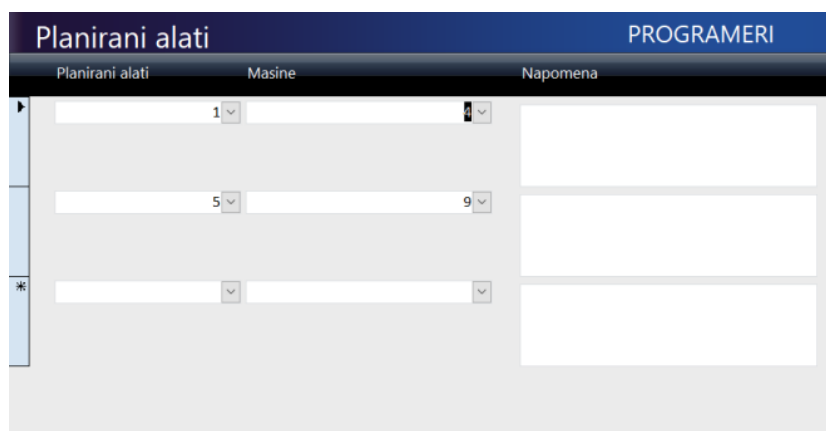

Slika 9. Interfejs planiranih alata

\section{ZAKLJUČAK}

Svako preduzeće teži modernizaciji, pre svega kroz primenu savremenih informaciono-tehnoloških unapređenja, uz minimalni stepen nesigurnosti razvoja, što na kraju daje višegodišnje uspešno poslovanje. Vreme pokazuje da se dešavaju radikalne promene u načinu poslovanja, a te promene dolaze sve brže. Njihovo neprihvatanje ili potpuno odbacivanje smanjuje konkurentnost preduzeća na tržištu, jer poslovanje u novije vreme postaje sve transparentije, pa se lakše može zaključiti na koji način preduzeće funkcioniše.

Cilj ovog rada je ispunjen tako što je detaljno prikazan problem upravljanja alatima u preduzeću, a rešenje je prikazano u obliku ideje, odnosno koncepta na koji bi se način taj problem mogao rešiti. Unapređenje $u$ komunikaciji zaposlenih pri upravljanju alatima $u$ preduzeću zauzvrat daje velike vremenske i novčane uštede. Zbog toga se nameće logičan zaključak da je ovakav sistem realno potrebno razviti i implementirati $u$ posmatrano preduzeće.

\section{LITERATURA}

[1] http://www.jomi-ing.com/saboutUs.html (pristupljeno u avgustu 2021.)

[2] D. Berić, "Model informacionog sistema za podršku upravljanju industrijskim preduzećima”, doktorska disertacija, Fakultet tehničkih nauka, Novi Sad, 2019.

[3] D. Lukić, M. Milošević, V. Todić, "Integrisani CAPP sistemi i tehnološka baza podataka”, skripta, Fakultet tehničkih nauka, Novi Sad, 2013.

[4] M. Stefanović, ,, CIM sistemi”, Mašinski fakultet, Kragujevac, 2006.

[5] D. Božić, "Informacioni sistem za praćenje toka alata u malom proizvodnom preduzeću", master rad, Fakultet tehničkih nauka, Novi Sad, 2021.

\section{Kratka biografija:}

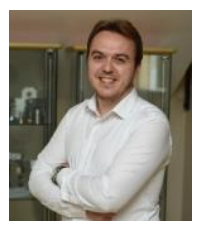

Dejan Božić rođen je u Bačkoj Topoli 1997. god. Master rad na Fakultetu tehničkih nauka iz oblasti Mašinstva Proizvodno mašinstvo, smer Računarom podržane tehnologije odbranio je 2021. god. kontakt: bbozic997@gmail.com 